\title{
MAXIMAL RESPIRATORY PRESSURES AND PULMONARY FUNCTION IN MALE RUNNERS
}

\author{
L. CORDAIN, PhD, B. J. GLISAN, MS, R. W. LATIN, PhD*, A. TUCKER, PhD** and J. M. STAGER, PhDt
}

Department of Exercise and Sport Science, Colorado State University, "School of Health, Physical Education and Recreation, University of Nebraska at Omaha,

* "Department of Physiology and Biophysics, Colorado State University and tDepartment of Health, Physical Education and Recreation, Indiana University

\section{ABSTRACT}

To determine the effects of long term exercise on respiratory muscle strength, maximal inspiratory $\left(P_{\mid}\right.$max) and expiratory ( $P_{E}$ max) pressures, pulmonary volumes and capacities and anthropometric parameters were measured in a group of 101 male runners aged 16 to 58 years. The runners exhibited significantly $(p<0.05)$ lower $P_{E} \max \left(202 \pm 41 \mathrm{~cm} \mathrm{H}_{2} \mathrm{O}\right.$ and significantly greater residual lung volumes (RV) $(2.08 \pm 0.49 \mathrm{~L})$ than predicted values for normal subjects of similar height and age. Forced vital capacities were not different $(p>0.05)$ from values reported for normal non-smoking populations. These data suggest that running may cause a non-pathological increase in RV, perhaps mediated by reductions in expiratory muscle strength. Additionally, current RV regression equations developed for normal subjects may be inappropriate for use in running populations.

Key words: Maximal respiratory pressures, Residual lung volume, Forced vital capacity, Exercise

\section{INTRODUCTION}

Previous studies of training programmes examining the respiratory muscles have shown that these muscles respond to exercise by increasing in strength and endurance (Leith and Bradley, 1976; Martin and Stager, 1981; Keens et al, 1977), similar to other skeletal muscles. Whether these changes occur in the respiratory muscles as a consequence of long term endurance exercise (e.g. running) has not been well documented (Cordain et al, 1982; Robinson and Kjeldgaard, 1982). Furthermore, it is unclear if changes in respiratory muscle strength can alter pulmonary volumes and capacities. In an attempt to answer these questions, we measured maximal inspiratory ( $P_{1}$ max) and expiratory ( $P_{E}$ max) pressures, pulmonary volumes and capacities, and anthropometric measurements in a large group of male runners.

\section{METHODS}

\section{Subject Selection}

The subjects consisted of 101 Caucasian, male runners between 16 and 58 years of age who had been participating in a running programme for at least one year with a minimum running frequency of three times per week. Subjects were selected from local high school and university cross-country teams as well as from area running clubs. All subjects were non-smokers (for at least five years) and to be free of known respiratory disease. Prior to the initiation of this study, approval was obtained from the Colorado State University Human Research Committee and informed consent was obtained from each subject.

\section{Anthropometry}

Prior to pulmonary measurements, anthropometric data were gathered. Measurements included chest girth $\left(\mathrm{G}_{\mathrm{C}}\right)$, distance from the jugular notch to the sternal notch (DJS) and the biacromical diameter (DBA). Measurements were made to the nearest $0.1 \mathrm{~cm}$ with a fibreglass anthropometric tape. Each landmark was measured in a standardised manner so that no more than $1 \%$ difference existed

Address for correspondence:

Dr. L. Cordain

Department of Exercise and Sport Science

Colorado State University

Fort Collins

CO 80523

USA between repeated trials. Height was measured with a medical-grade stadiometer to the nearest $0.1 \mathrm{~cm}$.

\section{Pulmonary Determinations}

All subjects were required not to have exercised within 12 hours of reporting to the laboratory for pulmonary function testing, since forced vital capacities (FVC) have been shown to be reduced, temporarily, following an acute exercise bout (Maron et al, 1979) whereas residual lung volumes (RV) have been shown to be temporarily increased (Girandola et al, 1977). All measurements were made while the subjects were seated and wore noseclips. Subjects made three FVC manoeuvres into a $13.5 \mathrm{~L}$ respirometer (Warren $\mathrm{E}$. Collins, Braintree, MA) with the largest value being used for data reduction. Residual lung volumes were determined using the closed circuit single breath, oxygen dilution technique (Wilmore, 1969) in conjunction with a modified 10L Stead-Wells spirometer (Warren E. Collins, Braintree, MA) and a nitrogen analyser (Ohio Medical Products, Madison, WI). The spirometer was filled with 7.0 litres of oxygen, and the seated, nose-clipped subjects took three or four normal breaths into a three-way mouthpiece that was opened to room air. After the subjects were asked to exhale maximally, the three-way valve was switched to the spirometer and the subjects were instructed to inspire and expire at two-thirds of their maximum, at a rate of one breath every three seconds. After equilibrium was reached (approximately 6-9 breaths), the subjects were instructed to take a maximal inspiration followed by a maximal expiration. The valve was then turned back to room air and the nitrogen reading at this point was recorded. Three trials were taken, with an interval of 20 minutes between trials, to allow the subject's lungs to be cleared of the $100 \%$ oxygen. Maximal inspiratory pressure measurements were made at $\mathrm{RV}$ and maximal expiratory measurements were made at total lung capacity (TLC) following the technique described by Black and Hyatt (1969). The mouthpiece, which occluded the airway, was constructed of thick, non-resilient plastic to prevent the pressures from being dissipated. A digital manometer (Validyne, Model PS 309, Northridge, CA) was interfaced to an IBM personal computer and a peakdetecting algorithm was designed to monitor and record maximal pressures. Pressures were measured consecutively until no further increases occurred, and the highest value was used for data reduction. Predictions of FVC (Berglund et al, 1963; Cotes et al, 1966; Goldman and Becklake, 1959; Kory et al, 1961; Morris et al, 1971; Needham et al, 1954) and RV (Boren et al, 1966; Goldman 
TABLE I

Subject characteristics by age

\begin{tabular}{|c|c|c|c|c|c|c|c|c|c|}
\hline Years & $n$ & $\mathrm{Ht}(\mathrm{cm})$ & Wt (kg) & FVC (L) & RV (L) & TLC (L) & $\mathrm{RV} / \mathrm{TLC} \times 100$ & 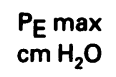 & $\begin{array}{l}P_{1} \max \\
\mathrm{cm} \mathrm{H} \mathrm{H}_{2} \mathrm{O}\end{array}$ \\
\hline $16-19$ & 22 & $178.2 \pm 5.7$ & $70.1 \pm 6.1$ & $5.31 \pm 0.53$ & $1.76 \pm 0.47$ & $7.07 \pm 0.86$ & $24.9 \pm 4.1$ & $207 \pm 43$ & $-142 \pm 26$ \\
\hline $20-29$ & 27 & $180.0 \pm 6.4$ & $72.9 \pm 9.7$ & $5.50 \pm 0.52$ & $1.99 \pm 0.53$ & $7.49 \pm 0.82$ & $26.6 \pm 4.7$ & $204 \pm 34$ & $-140 \pm 30$ \\
\hline $30-39$ & 25 & $175.5 \pm 6.1$ & $73.1 \pm 9.0$ & $5.36 \pm 0.42$ & $2.13 \pm 0.41$ & $7.49 \pm 0.67$ & $28.4 \pm 3.6$ & $202 \pm 46$ & $-122 \pm 22$ \\
\hline $40-49$ & 19 & $177.8 \pm 4.9$ & $80.7 \pm 10.6$ & $5.46 \pm 0.46$ & $2.41 \pm 0.33$ & $7.87 \pm 0.71$ & $30.6 \pm 3.1$ & $204 \pm 38$ & $-117 \pm 25$ \\
\hline $50-59$ & 8 & $178.3 \pm 5.2$ & $77.9 \pm 9.0$ & $4.68 \pm 0.71$ & $2.51 \pm 0.31$ & $7.19 \pm 0.73$ & $34.9 \pm 3.6$ & $178 \pm 46$ & $-111 \pm 25$ \\
\hline All groups & 101 & $177.9 \pm 5.9$ & $74.2 \pm 9.5$ & $5.36 \pm 0.53$ & $1.87 \pm 0.49$ & $7.23 \pm 0.81$ & $25.7 \pm 4.9$ & $202 \pm 41$ & $-130 \pm 28$ \\
\hline
\end{tabular}

Values are means \pm SD

and Becklake, 1959; Grimsby and Soderholm, 1963; Needham et al, 1954) were made from previously-reported equations. These data appear in Table IV.

\section{Statistical Analyses}

Differences between measured and predicted values for the pulmonary function parameters were determined using a repeated measures ANOVA. An all variable inclusive correlation matrix (Pearson's $r$ ) was developed to examine relationships among variables and stepwise multiple regression techniques were employed to develop the prediction equations for the present group of runners.

\section{Validation}

A similar, but independent group of subjects $(n=24)$ were assessed to determine the validity and generalisability of the prediction equations. Criterion measures of $P_{E}$ max, $P_{1}$ max, FVC, RV, TLC, and RV/TLC $\times 100$ were obtained from each subject by using the previously described techniques. Predictions of these measures were then computed from the equations developed in this study. Repeated measures ANOVAs were used to determine if systematic differences existed between the criterion and predicted means.

\section{RESULTS}

Subject characteristics for the entire sample as well as by ages appear in Table I. Mean PE max exhibited no significant $(P>0.05)$ relationship (Table II) to age, suggesting that expiratory muscle strength does not decline significantly after maturity in runners. However, in the 50 to 59 year age group, a $13 \%$ reduction in mean $\mathrm{PE}_{\mathrm{E}}$ max was noted. Conversely, mean $P_{\mid}$max exhibited a trend for decreasing pressure with increasing age, as reflected by the

TABLE ॥

Correlation matrix (Pearson Product Moment)

for selected subject measurements $(n=101)$

\begin{tabular}{lrrrrrrrr}
\hline & HT & $G_{C}$ & DJS & $D_{B A}$ & $R V$ & $P_{E} \max$ & $P_{\text {I max }}$ & FVC \\
\hline$G_{C}$ & 0.38 & & & & & & & \\
$D_{\text {JS }}$ & 0.12 & -0.06 & & & & & & \\
$D_{B A}$ & 0.30 & 0.25 & -0.13 & & & & & \\
RV & 0.35 & 0.32 & 0.02 & 0.03 & & & & \\
$P_{E}$ max & -0.04 & 0.20 & -0.10 & 0.17 & -0.16 & & & \\
$P_{\text {I } \max }$ & 0.07 & 0.11 & 0.09 & -0.20 & 0.28 & -0.56 & & \\
FVC & 0.48 & 0.17 & 0.20 & 0.20 & 0.26 & 0.09 & -0.04 & \\
AGE & -0.05 & 0.39 & 0.13 & -0.23 & 0.48 & -0.13 & -0.43 & -0.17 \\
& & & & & & & & \\
\hline
\end{tabular}

$r=0.32 p<0.001$ significant relationship ( $p<0.001, r=-0.43$ ) between age and $P_{\mid}$max. None of the pulmonary volumes and capacities measured in the present study showed significant relationships to either $P_{E}$ max or $P_{\mid}$max.

Except for the 50 to 59 year age group, no trend was apparent for the expected decline in FVC with increasing age, as reported in other large scale studies of normals. Forced vital capacity showed no significant $(p>0.05$, $r=-0.17$ ) relationship to age. Similar to studies of normals, there was an age-related increase in both RV and RV/TLC $\times$ 100. Residual lung volumes were significantly related to age $(p<0.001, r=0.48)$.

\section{TABLE III}

Multiple regression equations for the prediction of various pulmonary parameters $(n=101)$

\begin{tabular}{lccc}
\hline Equation & $R$ & $R^{2}$ & SEE \\
\hline$P_{E} \max \left(\mathrm{cm} \mathrm{H}_{2} \mathrm{O}\right)=-0.43(\mathrm{~A})+215^{*}$ & 0.13 & 0.017 & 41.0 \\
$P_{1} \max (\mathrm{cm} \mathrm{H} \mathrm{O})=0.99(\mathrm{~A})-161$ & 0.43 & 0.185 & 25.0 \\
$\mathrm{FVC}(\mathrm{L})=0.043(\mathrm{H})-0.0068(\mathrm{~A})-2.06$ & 0.50 & 0.250 & 0.47 \\
$\operatorname{RV}(\mathrm{L})=0.0204(\mathrm{~A})+0.0306(\mathrm{H})-3.99$ & 0.61 & 0.372 & 0.39 \\
$\operatorname{TLC}(\mathrm{L})=0.0732(\mathrm{H})+0.0132(\mathrm{~A})-6.21$ & 0.56 & 0.314 & 0.68 \\
$\operatorname{RV} / \mathrm{TLC} \times 100(\%)=0.245(\mathrm{~A})+18.2$ & 0.59 & 0.348 & 4.00
\end{tabular}

$A=$ age in years; $H=$ height in $\mathrm{cm}$

${ }^{*} p=0.24$, all other equations $p<0.001$

Simple and multiple regression equations employing age or age and height as predictors of pulmonary function variables appear in Table III. None of the three anthropometric chest dimensions were identified as significant predictors of any pulmonary function variable when forward stepwise multiple regression techniques were applied to the data. Of the six equations reported in

\section{TABLE IV}

Validation of prediction equations $(n=24)$

\begin{tabular}{lcccc}
\hline Variable & Criterion & Prediction & Error of Estimate & SEE \\
\hline$P_{E} \max \left(\mathrm{cm} \mathrm{H}_{2} \mathrm{O}\right)$ & 201.0 & 195.6 & 5.40 & 41.0 \\
$P_{1} \max \left(\mathrm{cm} \mathrm{H}_{2} \mathrm{O}\right)$ & -132.0 & -127.3 & 4.70 & 25.0 \\
FVC (L) & 5.28 & 5.33 & 0.05 & 0.47 \\
RV (L) & 1.94 & 2.10 & 0.16 & 0.39 \\
TLC (L) & 7.27 & 7.37 & 0.10 & 0.68 \\
RV $/ \mathrm{TLC} \times 100(\%)$ & 26.7 & 27.1 & 0.40 & 4.00 \\
& & & &
\end{tabular}

All error of estimate values $p>0.05$ 
Table III, only the equation for $P_{E}$ max was not a significant ( $p=0.24$ ) predictor of pulmonary function. The equations reported in Table III were cross-validated within a similar but independent group of runners $(n=24)$, and no significant differences $(p>0.05)$ were demonstrated between any of the observed measurements and those predicted from the equations in Table III. Also, all of the error of estimates fell within one SEE of each equation. These validations may be seen in Table IV.

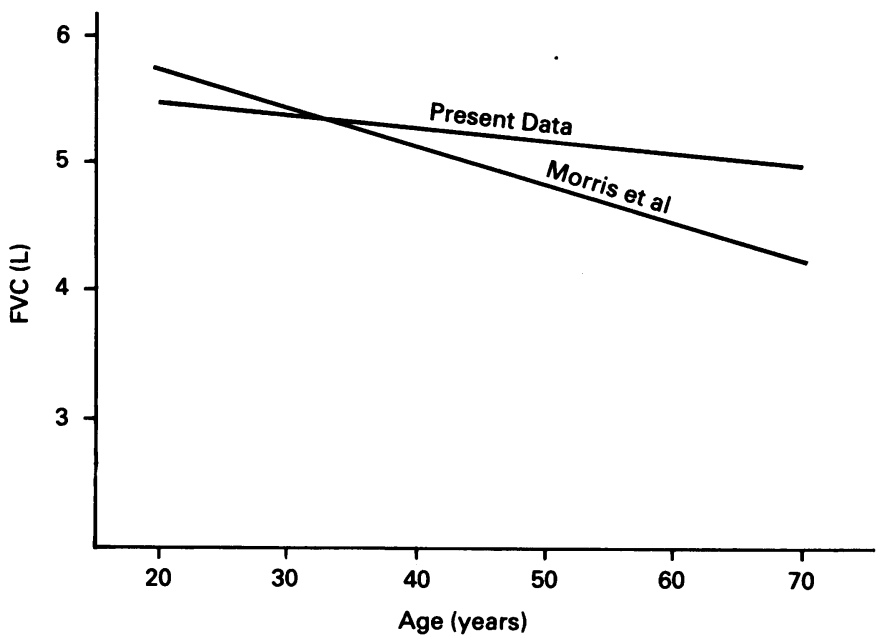

Fig. 1: Relationship of FVC to age in normal non-smokers and in runners.

Predicted values for FVC were calculated from six equations reported for normals. Observed values were significantly larger $(p<0.05)$ than values predicted from five of six regression equations (Table V). Only in the study by Morris et al (1971), who evaluated FVC in a large sample of non-smokers, was there no difference between observed and predicted values. Observed values for RV were significantly larger $(p<0.05)$ than predicted for four previously reported RV regression equations, while observed $P_{E}$ max values were significantly lower $(p<0.05)$ than those reported for normals by Black and Hyatt (1969). These results may also be seen in Table $V$.

\section{TABLE V}

Comparison of observed and predicted values $(n=101)$

\begin{tabular}{|c|c|c|c|c|}
\hline Source & Observed & Predicted & $\begin{array}{l}\text { Per cent of } \\
\text { Predicted }\end{array}$ & Difference \\
\hline \multicolumn{5}{|l|}{ FVC (L) } \\
\hline Berglund et al, 1963 & 5.36 & 5.13 & 104.5 & 0.23 \\
\hline Goldman et al, 1959 & 5.36 & 5.09 & 105.3 & 0.27 \\
\hline Needham et al, 1954 & 5.36 & 4.71 & 113.8 & 0.65 \\
\hline Kory et al, 1961 & 5.36 & 5.04 & 106.3 & 0.32 \\
\hline Morris et al, 1971 & 5.36 & 5.35 & 99.8 & $0.01 *$ \\
\hline Cotes et al, 1966 & 5.36 & 5.07 & 105.7 & 0.29 \\
\hline \multicolumn{5}{|l|}{ RV (L) } \\
\hline Goldman et al, 1959 & 2.08 & 1.88 & 110.5 & 0.20 \\
\hline Needham et al, 1954 & 2.08 & 1.92 & 108.6 & 0.16 \\
\hline Boren et al, 1966 & 2.08 & 1.50 & 139.1 & 0.58 \\
\hline Grimby et al, 1963 & 2.08 & 1.55 & 134.2 & 0.53 \\
\hline \multicolumn{5}{|l|}{$P_{E} \max \left(\mathrm{cm} \mathrm{H} \mathrm{H}_{2} \mathrm{O}\right)$} \\
\hline Black \& Hyatt, 1969 & 202.0 & 236.0 & 85.6 & -34.0 \\
\hline \multicolumn{5}{|l|}{$P_{1} \max \left(\mathrm{cm} \mathrm{H}_{2} \mathrm{O}\right)$} \\
\hline Black \& Hyatt, 1969 & -130.0 & -126.0 & 103.2 & $-4.0^{*}$ \\
\hline
\end{tabular}

* $p>0.05$, all other differences $p<0.05$

\section{DISCUSSION}

The results of the present study demonstrate that runners have $P_{\text {I }}$ max values similar to values reported by others (Table VI), but have values for PE max lower than observed in other studies of normals. These data suggest that running programmes of longer than one year in duration may decrease maximal expiratory pressures. Ringqvist (1966) suggested that changes in airway resistance served as a major stimulus for respiratory muscle hypertrophy.

TABLE VI

Maximal static pressures

\begin{tabular}{lrrr}
\hline Source & $n$ & $\begin{array}{c}P_{1} \max \\
\mathrm{cm} \mathrm{H}_{2} \mathrm{O}\end{array}$ & $\begin{array}{l}\mathrm{PE}_{E} \max \\
\mathrm{cm} \mathrm{H}_{2} \mathrm{O}\end{array}$ \\
\hline Black \& Hyatt, 1969 & 36 & $-124 \pm 22$ & $233 \pm 42$ \\
Cook et al, 1964 & 17 & $-133 \pm 39$ & $237 \pm 45$ \\
Ringqvist, 1966 & 82 & $-130 \pm 32$ & $237 \pm 46$ \\
Present group & 101 & $-130 \pm 28$ & $202 \pm 41$ \\
\hline
\end{tabular}

Values are means \pm SD

Since airway resistance is related inversely and curvilinearly to lung volumes (Briscoe and Dubois, 1958), then airway resistance will be reduced when subjects breathe at high lung volumes (West, 1984). Pyorala et al (1968) pointed out that endurance athletes maintain lower and deeper rhythms of breathing, both at rest and at exercise than compared to normals. Therefore, the reduced $P_{E}$ max demonstrated in the present runners may be resultant from long-term reductions in airway resistance from breathing at high lung volumes both at rest and during exercise. It is relevant to point out that as FRC is reduced during exercise in normal subjects breathing is accomplished at lower lung volumes; however, the mean lung capacity increases, hence the average resistance is likely to be lower over the entire breath. Maximal inspiratory pressure were similar to values reported in normals, indicating that running provides no additional stimulus for inspiratory muscular strength.

In the present study, all of the subjects were nonsmokers, whereas in several previous studies of $P_{E} \max$ (Black and Hyatt, 1969; Cook et al, 1964; Ringqvist, 1966), as well as in studies of RV (Goldman and Becklake, 1959; Needham et al, 1954; Boren et al, 1966; Cook et al, 1964), subjects included both smokers and non-smokers. Smoking could increase expiratory muscle strength by inducing a muscular training effect brought about by increased expiratory flow resistance or by chronic coughing. Therefore, it is possible that differences in $P_{E}$ max, and perhaps RV, demonstrated in the present group of runners relative to normals, resulted from differences in smoking habits.

The single breath oxygen dilution technique has been shown to underestimate RV by approximately 6 per cent when compared with other multiple breath techniques (Sterk et al, 1980), particularly in smokers and others with airway obstruction. However, in the present study only nonsmokers were tested, and the measured mean RV was greater than estimated values from four prediction equations (Table V). Therefore, it is likely that the elevated RV demonstrated in runners with the present technique would be slightly larger should other multiple breath techniques have been employed. 
In one of the few longitudinal studies to examine respiratory strength changes with running programmes, Robinson and Kjelgaard (1982) reported a $14.4 \%$ increase in expiratory pressures in a group of 11 adults $(8$ females and 3 males) at the end of 20 weeks. No changes occurred in maximal inspiratory pressures with running training. The maximal inspiratory pressure data of the present study is in agreement with the notion that running causes little change in inspiratory muscle strength. However, it is difficult to compare the expiratory strength changes observed by Robinson and Kjeldgaard (1982) with the present data, since values for both men and women were combined in the earlier study. Women comprised 8 of 11 subjects in that study and, since women have maximal expiratory pressure $30 \%$ lower than males (Ringqvist, 1966), the mean value for $P_{E}$ max, even after 20 weeks of training, was considerably lower than that observed in the present study (156 vs 202 $\mathrm{cm}_{2} \mathrm{O}$ ). Additionally, the values of the previous study were taken after five months of training, whereas the subjects in the present study had trained for a minimum of one year.

Flow-volume and volume-time curves illustrate that the limitation to RV in healthy subjects is primarily static where a balance exists between opposing chest wall and lung elastic recoil forces (Leith and Mead, 1967). Thus a reduction in expiratory muscle strength would be expected to result in an increased RV. In support of this runners of all age groups in the present study exhibited a significantly larger RV than predicted, while exhibiting a significantly lower PE max than predicted. Other cross-sectional studies that examined individuals who have been engaged in aerobic activities for many years, show that these endurance athletes maintain elevated values for RV and FRC (Pyorala et al, 1968; Eriksson et al, 1978; Kaufmann et al, 1974; Magel and Anderson, 1969; Maksud et al, 1971). Both Pyorala et al (1968) and Maksud et al (1971) speculated that an elevated FRC would tend to minimise fluctuations in alveolar gas tensions during the slower and deeper pattern of breathing exhibited by endurance athletes.

Short-term (6-12 weeks)'longitudinal studies have shown that RV decreases in subjects undertaking an aerobic training programme (Bachman and Horvath, 1968; Girandola, 1976; Girandola and Katch, 1973; Katch, 1971; Katch et al, 1969; Lynch et al, 1968; Swenson and Zauner, 1967; Wilmore et al, 1970), and it has been hypothesised that these reductions are resultant from increased strength of the respiratory expiratory muscles (Cordain et al, 1982; Girandola and Katch, 1973). This reduction in RV with aerobic training may only be a transitory effect. Swenson and Zauner (1967) demonstrated a $25 \%$ reduction in RV in 10 sedentary men after two weeks of conditioning; however, after eight weeks of training, only a $9.4 \%$ reduction was noted. Thus, it may be that $R V$ is initially reduced by increased expiratory muscle strength, but eventually, after a year or more of aerobic training, reductions in airway resistance, brought about by breathing at high lung volumes, serve to reduce expiratory muscle strength, thereby increasing RV.

In the present study observed FVC was not different from that predicted by the equation of Morris et al (1971) whose sample consisted entirely of healthy, non-smokers. However, observed FVC values were significantly larger than five predicted values (Table V) in which equations were developed from both smokers and non-smokers. These data suggest that running causes little or no change in FVC in healthy, non-smoking populations. Although exercise may not cause increases in FVC, it may be responsible for slowing the decline in FVC normally associated with aging. Pyorala et al (1968) noted that the decrease in FVC occurred less rapidly in a group of former champion endurance athletes. The results of the present study also support this observation with differences occurring after age 33.

Since the current study is of a cross-sectional nature, it is difficult to determine more precisely whether differences in pulmonary function between runner and normals occur as an adaptation to exercise or simply are a result of selection. Additionally, a control group was not used in this study; therefore, the interpretation of the treatment effects were somewhat compromised. Should systematic errors have occurred in the measurement of the pulmonary variables, it would be inappropriate to compare the present results with other studies. Further longitudinal studies of greater than one year, evaluating pulmonary changes in runners, are needed to determine more precisely mechanisms responsible for the larger RV demonstrated in these individuals.

\section{ACKNOWLEDGEMENTS}

This study was supported in part by Colorado State University, College of Professional Studies Grant \#22-2170.

\section{References}

Bachman, J. and Horvath, S., 1968 "Pulmonary function changes which accompany athletic conditioning programs". Res.Quart. 39: 235-39.

Berglund, E., Birath, G., Bjure, J., Grimby, G., Kjellmer, I., Sandqvist, L. and Soderholm, B., 1963 "Spirometric studies in normal subjects: I. forced expirograms in subjects between 7 and 70 years of age". Acta Med. Scand. 173: 185-92.

Black, L. and Hyatt, R., 1969 "Maximal respiratory pressures: normal values and relationship to age and sex". Am.Rev.Respir.Dis. 99: 696-702.

Boren, H., Kory, R. and Syner, J., 1966 "The lung volume and its subdivision in normal men". Am.J.Med. 41: 96-114.

Briscoe, W. and Dubois, A., 1958 "The relationship between airway resistance, airway conductance and lung volume in subjects of different age and body size". J.Clin. Invest. 37: 1279-85.

Cook, C., Mead, J. and Orzalesi, M., 1964 "Static volume-pressure characteristics of the respiratory system during maximal efforts". J.Appl. Physiol. 19: 1016-22.

Cordain, L., Ruhling, R. and Hintze, T., 1982 "Ventilatory muscle strength responses to aerobic training in women". Med.Sci.Sports Exerc. 14: 132 (abstr.).

Cotes, J., Rossiter, C., Higgins, I. and Gilson, J., 1966 "Average normal values for the forced expiratory volume in white caucasian males". Brit.Med.J. 1: 1016-19.

Eriksson, B., Engstrom, I., Karlberg, P., Lundin, A., Saltin, B. and Thoren, C., 1978 "Long term effect of previous swim training in girls: a ten year follow-up of the 'girl swimmers'". Acta Paed.Scand. 67: 285-92.

Girandola, R., 1976 "Body composition changes in women: effects of high and low exercise intensity". Arch.Phys.Med.Rehab. 47: 297-300.

Girandola, R. and Katch, V., 1973 "Effects of nine weeks of physical training on aerobic capacity and body composition in college men". Arch.Phys. Med.Rehab. 54: 521-24.

Girandola, R., Wiswell, R., Mohler, J., Romero, G. and Barnes, W., 1977 "Effects of water immersion on lung volumes: implications for body compositional analysis". J.Appl.Physiol. 43: 276-79.

Goldman, H. and Becklake, M., 1959 "Respiratory function tests: normal values at median altitude and the prediction of normal results". Am.Rev.Tuber. 79: 457-67.

Grimby, G. and Soderholm, B., 1963 "Spirometric studies in normal subjects, III static lung volumes and maximal voluntary ventilation in adults with a note on physical fitness". Acta Med.Scand. 173: 199-206.

Katch, F., 1971 "Pre- and post-test changes in the factors that influence computed body density changes". Res.Quart. 42: 280-85.

Katch, E., Michael, E. and Jones, E., 1969 "Effects of physical training on the body composition add (sic) diet of females". Res.Quart. 40: 99-104.

Kaufmann, D., Swenson, E., Fencl, J. and Lucas, A., 1974 "Pulmonary function of marathon runners". Med.Sci.Sports 6: 114-17.

Keens, T., Krastins, I., Wanamaker, E., Levinson, H., Crozier, D. and Bryan, A. 1977 "Ventilatory muscle endurance training in normal subjects and patients with cystic fibrosis". Am.Rev.Respir.Dis. 116: 853-60. 
Kory, R., Callahan, R., Boren, H. and Syner, J., 1961 "The veterans administration-army cooperative study of pulmonary function: clinical spirometry in normal men". Am.J.Med. 30: 243-58.

Leith, D. and Bradley, M., 1976 "Ventilatory muscle strength and endurance training". J.Appl.Physiol. 41: 500-16.

Leith, P. and Mead, J., 1967 "Mechanisms determining residual volume of the lungs in normal subjects". J.Appl.Physiol. 23: 221-27.

Lynch, P., Bove, A., Barrera, F. and Balfour, R., 1968 "Cardiovascular and respiratory studies on skin divers following physical training". Arch. Environ. Health 17: 91-97.

Mangel, J. and Anderson, K., 1969 "Pulmonary diffusing capacity and cardiac output in young trained Norwegian swimmers and untrained subjects". Med.Sci.Sports 1: 131-39.

Maksud, M., Hamilton, L., Coutts, K. and Wiley, R., 1971 "Pulmonary function measurements of olympic speed skaters from the U.S.". Med.Sci.Sports 3: 66-71.

Maron, M., Hamilton, L. and Maksud, M., 1979"Alterations in pulmonary function consequent to competitive marathon running". Med.Sci.Sports 11: 244-49.

Martin, B. and Stager, J., 1981 "Ventilatory endurance in athletes and nonathletes". Med.Sci.Sports Exerc. 13: 21-26.

Morris, J., Koski, A. and Johnson, L., 1971 "Spirometric standards for healthy non smoking adults". Am.Rev.Respir.Dis. 103: 57-67.
Needham, C., Rogan, M. and McDonald, I., 1954 "Normal standards for lung volumes, intrapulmonary gas mixing, and maximum breathing capacity". Thorax 9: 313-25.

Pyorala, K., Heinonen, A. and Karvonen, M., 1968 "Pulmonary function in former endurance athletes". Acta Med.Scand. 183: 263-73.

Ringqvist, T., 1966 "The ventilatory capacity in healthy subjects: an analysis of causal factors with special reference to the respiratory forces". Scand. J.Clin.Lab.Invest. 18 (supplement 88): 1-179.

Robinson, E. and Kjeldgaard, J., 1982 "Improvement in ventilatory muscle function with running". J.Appl.Physiol. 52: 1400-06.

Sterk, P., Quanjer, P., van der Maas, L., Wise, M. and vander Lende, R., 1980 "The validity of the single breath nitrogen determination of residual volume". Bull.Europ.Physiopath.Resp. 16: 195-213.

Swenson, E. and Zaunder, C., 1967 "Effects of physical conditioning on pulmonary function and working capacity in middle aged men". Scand.J. Res.Dis. 48: 378-83.

West, J., 1984 "Respiratory physiology". Baltimore: Williams and Wilkins, 104.

Wilmore, J., 1969 "A simplified method for determination of residual lung volumes". J.Appl.Physiol. 27: 96-100.

Wilmore, J., Royce, J., Girandola, R., Katch, F. and Katch, V., 1970 "Physiological alterations resulting from a 10 week program of jogging". Med.Sci.Sports 2: 7-14. 